\title{
An Update on Male Contraception
}

\author{
Ghulam Nabi (Corresponding author) \\ M. Phil Scholar. Department: Animal sciences \\ Reproductive neuro-endocrinology Lab: Quaid-i-Azam University, (Islamabad) Pakistan \\ Tel: 92-345-811-2741Ｅ-mail: ghulamnabiqau@gmail.com
}

\begin{abstract}
Muhammad Amin
M. Phil Scholar, Department of Zoology, University of Karachi, Pakistan

Tel: 92-315-902-0833Ｅ-mail: aminmuhammad013@yahoo.com
\end{abstract}

\begin{abstract}
Riaz Akhtar
MD and PG, surgery. Senior medical officer in Al-shifa medical center

Tazagram, district Dir lower, KPK, Pakistan

Tel: 92-347-848-4633 E-mail: riaz-akhtar54@yahoo.com
\end{abstract}

Muhammad Younas

DVM. University of agriculture Peshawar, KPK, Pakistan

Tel: 92-346-936-2779 E-mail: younas_sociologist@yahoo.com

Received: July 26, 2014 Accepted: August 11, 2014

doi:10.5296/jbls.v6i1.6057 URL: http://dx.doi.org/10.5296/jbls.v6i1.6057

\begin{abstract}
Women are focused for family planning from a very long time instead of men. For family planning no attention has been given to men, therefore in the market most of the contraceptive methods are female oriented. This may be due to their greatest stake and interest for family planning. In developing countries neglecting men for developing reliable and acceptable contraception is due to lack of or less participation in family planning. For family planning neglecting men is a losing strategy, resulting serious consequences for both partners. Therefore
\end{abstract}


the problem of abrupt population growth cannot be solved by giving attention to females only.

Keywords: Family planning, Contraception, Population

\section{Introduction}

During 2011 the world population was $\sim 6.9$ billion, and an increased in this population occurs at the rate of 80 million persons a year (Roth and Amory, 2011). By the year 2050, the World population will surpass 9 billion, causing a serious menace to food supplies and global ecology. Majority of the population growth occurs due to lack of access or improper use of contraception. According to Henshaw, 1998; Finer and Henshaw 2003; Besculides and Laraque, 2004 and Goto et al., 2006, half of all conception and half of all resulting pregnancies are unplanned and undesirable resulting into unintended population growth. In majority of the cases, half of the unintended pregnancies results due to failure to use any contraception, while the other half results due to method failure or difficulties with using contraceptives. In some poor nations due to economic crisis and cultural pattern there is very limited or no access to most of the available contraceptive methods. As a result unintended pregnancies established that results unwanted children who suffer a lot from neglect and poverty disproportionately. In particular, to cope with this problem very little attention has been given to develop safe, potent and economical male contraceptives. This has been reported that a lot of men accept safe and reversible contraceptives. Similarly majority of women also responded that, for avoiding pregnancy they would be willing to accept a male spouse practicing some sort of acceptable contraceptives. But in spite of such advantages, very little attention has been given to male contraceptives as compared to female contraceptives. As a result in the market most of the contraceptive methods are female oriented. This would be a very loosing strategy to neglect men in the control of family planning. This can cause serious concerns for both women and men. This review will highlight recent available traditional, herbal, pharmacological, hormonal, surgical, non-surgical non pharmaceutical and immune- contraceptives with their advantages and possible adverse effects.

\section{Contraception}

Contraception is defined as the planned avoidance of pregnancies through the use of various chemical drugs, surgical procedures, sexual practices or devices. Thus, any agent can be considered contraceptive whose ultimate goal is to prevent conception. Effective contraception in any social milieu allows partner to enjoy sexual relations without having children. At the same time it also allows the couple to have children when desired. The goal is to attain this with full privacy and comfort. Similarly, at the same time these contraceptives should be economical and free from hazardous effects. Some contraceptive methods like condoms (male and female) along with contraception also protect the partners from sexually transmitted diseases. (Rakhi and Sumathi, 2011).

\subsection{Why Female Uses So Much Contraceptive As Compared To Males}

For family planning women as compared to male have the utmost concern and stake. In addition they also have a great number of contraceptive choices. This is because women have the greatest stake and interest as far as family planning is concerned. They have a wide range of 
contraceptive choices. Women stand an uneven portion of the health and economic values of gestation and child rearing (Fanuel, 2011).

\subsection{Need for Male Contraception}

There are a lot of reasons that why couple uses contraceptives. These reasons may include complete freedom from children, spacing birth, postponing childbearing and regulating family size. All these reason depends on the couple age, aim of contraception and type of partner relations. All the contraceptive methods available in the market do not fulfill the diverse and dynamic personal needs of partners in their reproductive age and in the widely different religious, cultural, geographical and availability settings throughout the world. For effective and safe fertility regulation this is necessary to increase the numbers of contraceptive choices for each partner. However, due to shortcomings of some of the currently available male contraceptives methods are a great hindrance to involve men in family planning. To control population explosion and its related ecological destructions, this is very crucial to actively involved both men and women for family planning (Fanuel, 2011).

\subsection{Characteristics of Male Contraceptives}

Before men receive a contraceptive method certain prerequisites must be realized. They would be effective and acceptable to both partners. These contraceptive must be rapidly effective and free from hazardous effects. These methods in respect to fertility would be reversible and without influence on offspring. They would be cheap and easily available (Nieschlag and Bhere, 2001).

Methods on the basis of actions: There are three methods

(1) Those checking transportation of sperm into the female reproductive tract.

(2) Those inhibiting sperm formations.

(3) Those stopping sperm maturation (Nieschlag and Bhere, 2001).

\section{Types of Contraceptive Methods}

\subsection{Traditional Methods: It include the followings}

\section{Coitus interrupts or withdrawal}

In this method prior to ejaculation penis is withdrawn from the vagina, thus avoiding the sperm to enter into the female reproductive tract. This is a very oldest contraceptive method and totally relies on the control and cooperation of male spouse. But this contraceptive method is not a reliable because, before ejaculation spermatozoa may discharge inside the tract or left on the external genitalia leading to contraceptive failure. For the success of this method, both physically and emotionally good self-control is obligatory. This method costs nothing, needs no additional things and is fully side effects free. The only disadvantages are failure and pleasure reduction (Rakhi and Sumathi, 2011). 


\section{Lactational Amenorrhea Method}

In nursing women due to secretion of hormones, conception is prevented for about of 6 months. This persists if there is full breast feeding during day and night and no menses at all. This is more a myth as, breast-feeding is uneven and about $60 \%$ women start menstruating by the third month. This method also failed in condition such as breast abscess, inverted, cracked or sore nipples and when baby sleeps through the night. Numerous unsuspecting women during this period conceive before reoccurrence of menstruation (Rakhi and Sumathi, 2011).

\section{Rhythm Method}

This method requires predicting the time when ova is releasing from the ovary (ovulation). During this time the women is more fertile. Body temperature, menstrual pattern, alteration in cervical mucus or a combination of these is recorded to predict ovulation (symptom-thermal method). Sexual intercourse is prohibited on fertile days. A lot of people claim having knowledge about identification of these fertile days but, in reality a minor proportion of people can accurately predict ovulation timing. This method is not appropriate for women having irregular menstrual cycle, or after childbirth, or during menopausal years. Intercourse is limited to some days of the month only. The method carefully required record keeping for calculating the safe period (Rakhi and Sumathi, 2011).

\section{Heat based contraception}

This method dates back to the concept of Hippocrates. In this method testes are heated until, unable for sperm formation (spermatogenesis). Testes are heated for 45 minutes at $116 \mathrm{~F}\left(47^{\circ} \mathrm{C}\right)$ just below the threshold of pain. This method is not a broadly attractive technique because of severe side effects (Christina and Ronald, 2010).

\section{Condoms}

Prior to sexual intercourse, on the erect penis is rolled a thin rubber or latex sheath (condom). Condom checks semen (sperms) from inflowing into the female reproductive tract. This method has $95 \%$ effectiveness if used appropriately. The use of condoms is safe and can be used by all age groups. To use condom there is no need to consult physician for medical examination. Condoms has dual benefits, in addition to contraception it also provides protection from sexual transmitting diseases (STDs). However incorrect use, inconsistency and compliance are the main shortcoming associated with this method. There are drawbacks deep-down to this practice, as it may tear or slip if not used appropriately. Perforated and expired condoms should not be used (IIPS and ORG, 2000; Rakhi and Sumathi, 2011).

\subsection{Herbal Medicines}

Chemical agents and plant products have been labeled as possible male antifertility means in the hope of emerging a functioning male contraceptive. Herbal contraceptives can help the couple to control their fertility without consulting a physician. Herbal contraceptives have fewer side effects and are readily available. They protect the privacy and can possibly increase the number of couples to practice family planning. Some of the herbal medicines are discussed as follow; 


\section{Gossypol}

It is a natural constituent of cotton seed oil which is used for cooking in china. In certain villages it induces pronounced infertility that provoke intensive search for the cause. It causes irreversible damage to germ cells epithelium. Gossypol occurs in two isomeric forms, differing in their toxicity and fertility (Nieschlag and Bhere, 2001 a).

\section{Tripterygium wilfordii}

It originates in traditional Chinese medicine, but the toxic effects prevent clinical application. No side effects free substances has been isolated that maintain effectiveness (Nieschag and Bhere, 2001 a). In china it was also used for the treatment of rheumatoid arthritis, fever, thrombocytopenic purpura, ankylosing spondylitis, chronic nephritis, chronic hepatitis, and many skin diseases (Qian, 1987). Azospermia was observed in rheumatoid arthritis patients treated with Tripterygium wilfordii for a total of 2 to 56 month (Yu, 1983). Similarly Tripterygium wilfordii in Wistar rats causes destruction of seminiferous epithelium, reduction in serum testosterone level, (Zheng et al., 1985) sperm concentration and sperm motility (Qian et al., 1986). These studies confirm the antifertility effects of this plant.

\section{Oldenlandia Affinis}

Oldenlandia affinis has an antifertility effect. This was reported in sexually mature male rats $(n=8)$ that when extract of this plant were administered intraperitoneally at a dose of $24 \mathrm{mg} / \mathrm{rat}$ $(n=8)$ for a total of eight injections over a 4 week period, a reduction in testicular weight but no change in the weight of all other accessory sex organs and vital organ were investigated. Testis histology in treated group showed azoospermic or fewer spermatozoa seminiferous tubules as compared to control group, however there was no any alteration in sertoli cell morphology or tubule thickness. $O$. affinis in treated group caused a $17 \%$ reduction in sperm motility but epididymal sperm count was not affected. Similarly in the experimental group, there was a significant reduction in serum testosterone levels as compared to control group. These preliminary results indicate that in male rats fertility is suppress by the aqueous leaf extract of O. affinis (Mavi, 2000; Chauhan et al., 2007; Kenjale et al., 2008; Mishra and singh, 2009; Sewani-Rusike and Gundidza, 2011). Further studies are needed to investigate the toxicity and site of actions of this plant.

\section{Carica papaya}

The Carica papaya seed extract has antifertility effects. The extract had a post-testicular action and the effects were stated to be reversible upon withdrawal of treatment (Das, 1980; Lohiya et al., 1992; Chinoy et al., 1995; Fanuel, 2011).

\section{Azadirachta indica}

This has been reported that, the leaf extract of this plant when administer to male rats alter the morphology and physiology of testis and spermatozoa. In male rats some studies have documented that, Azidirachta indica leaves has antiandrogenic effects. Ethanol extract 
obtained from the bark and flower of Azidirachta indica can cause reversible infertility in male rats by interfering with spermiogenesis at the late spermatids level (Dixit et al., 1992; Shaikh et al., 1993; Kasturi et al., 1995; Fanuel, 2011).

\section{Balanites roxburghi and Phyllanthus amarus}

They also shows anti spermatogenic effects (Rao et al., 1997a ; Rao et al., 1997b ; Fanuel, 2011).

\subsection{Others Pharmacological Drugs: It include the followings}

\section{Adjudin and Gamendazole}

It is a derivative of ionidamine, which was developed as an anticancer. Initial studies with lonidamine demonstrated that oral administration to adult rats $(50-200 \mathrm{mg} / \mathrm{kg}$ ) induced depletion of germ cells from the seminiferous epithelium, resulting in infertility. At the ultrastructural level, ionidamine was shown to noticeably cause retraction of the apical cytoplasm in sertoli cells (Mruk et al., 2008).

\section{Inhibiting vitamin A metabolism as an approach to male contraception}

In rodents for spermatogonial differentiation vitamin A is known to be very crucial; whether in primates this is also the case is not clear. When adult male mice are made vitamin-A deficient (VAD) for 2-3 month via feeding them on a vitamin A-deficient diet, in the seminiferous epithelium all differentiated germ cells are vanished and only sertoli cells and type A spermatogonia persist. This indicates that in adult rodent testis, the ability of spermatogonial differentiation is block by removing retinoic acid (RA). It is currently not reported that in primates whether VAD blocked spermatogonial differentiation. In the third world countries human cases of VAD have been noticed however, the corelationship between VAD and fertility has yet to be published. A VAD study in nonhuman primates is necessary to determine whether eliminating RA in the primate testis also results in a block during spermatogonial differentiation (Hogarth et al., 2011).

\section{Indenopyridine (CDB-4022)}

In various species such as monkeys, mice, dogs and rats indenopyridine reveals reversible antispermatogenic action. A single oral dose of $l$-CDB-4022 $(2.5 \mathrm{mg} / \mathrm{kg})$ can leads to significant reduction of testicular weight however, rate of body weight gain was not compromised. Serum hormones like inhibin B was significantly reduced, FSH was increased but LH, testosterone and activin A was not changed (Cook et al., 1995; Cook et al., 1997; Hild and Reel, 2000; Sailaja et al., 2008).

\section{Pyrimethamine}

Pyrimethamine (PYR) in male mice in a dose dependent fashion causes male infertility and spermatogenic arrest. Furthermore, normal fertility was induced back in all animal species upon termination of drug administration. It is also suggested that the action of PYR is due to its antifolate action. Thus, PYR represents another approach toward development of a male contraceptive (Cosentino et al., 1990). 
Bis-(dichloroacetyl)-diamines (BDADs)

BDADs are compounds that inhibit spermatogenesis and function as male contraceptives in many species. The bis-(dichloroacetyl)-diamines (BDADs) are a set of compounds that target the aldehyde dehydrogenases and prevent the oxidation of retinaldehyde to RA. Nearly 50 years ago, one particular BDAD, WIN 18,446, was shown to completely and reversibly inhibit spermatogenesis in men when dosed orally (Hogarth et al., 2012).

\section{Sulfasalazine}

It leads to male disturbed fertility by interfering with sperm maturation rather than spermatogenesis. Toxic side effects make the substance unsuitable for contraception (Nieschlag and Bhere, 2001 a).

\section{Nitroimidazole derivatives}

They are used as antibiotics and against protozoan can also leads to suppressed fertility by inhibiting sperm maturation in the epididymis. In general the spectrum of side effects makes long term use, as would be required for contraception, impossible. One example is Ornidazole (Nieschlag and Bhere, 2001 a).

\section{Calcium channel blocker}

Ion channels play a key role in maturation, capacitation and acrosome reaction of sperms. Blockade of calcium channels with pharmacological inhibitors or compounds isolated from plant extracts might be suggested as one of promising mechanisms of future male contraceptives (Driak and Swandova, 2013).

\subsection{Hormonal Contraception}

The principle of male hormonal contraception is based on (1) suppression of LH and FSH. (2) Elimination of intratesticular testosterone. (3) Substitution of peripheral testosterone to maintain androgenicity (Nieschlag and Bhere, 2001b). Male hormone contraceptive inhibit spermatogenesis by suppression the hypothalo-pituitary gonadal (HPG) axis. Gonadotropin releasing hormone $(\mathrm{GnRH})$ is released normally from the hypothalamus. $\mathrm{GnRH}$ has receptors on the pituitary gland and causes the secretion of follicle-stimulating hormone (FSH) and luteinizing hormone (LH) from it. LH function is to synthesize testosterone in Leydig cells by binding to it in the testicular interstitium. (Roth and Amory, 2011). In the seminiferous tubules, this intratesticular testosterone stimulates spermatogenesis along with FSH. Testosterone also enters into the blood stream and regulates its synthesis via negative feedback at hypothalamus and pituitary level. LH and FSH secretions are suppressed by administration of testosterone, leading to reduced sperm count in most men by altering testicular signals mandatory for spermatogenesis. However this sort of suppression is reversible. Some of the hormonal contraceptives are discussed below.

\section{Testosterone enanthate}

By injecting 200mg of testosterone ennathate i.m to volunteers, azospermia was achieved with in first six months. There are also ethnic differences in the suppressibility of spermatogenesis 
(WHO, 1996; Nieschlag and Bhere, 2001 b; Ly et al., 2005; Cheng and Mruk, 2010).

\section{9- Nortestosterone}

It is effective than testosterone enanthate, and injected every 3 weeks enabled azoospermia (Nieschlag and Bhere, 2001 b).

\section{Testosterone Buciclate}

A testosterone ester show a long effective phase of 3-4 months after a single injection of 1200 mg (Nieschlag and Bhere, 2001 $1_{b}$.

\section{Testosterone decanoate}

Injections of testosterone decanoate along with oral etonogestrel (300 $\mu \mathrm{g}$ daily) for 4-6 weeks reduces sperm count about one million in per ML ejaculate. This sperm reduction was very abrupt and was associated with very minor side effects (Hay et al., 2005).

\section{Testosterone Undecanoate}

When administered orally, it has no effects in suppressing spermatogenesis however, intramuscular injection shows a prolong half-life makes it an interesting contraceptive candidates (Nieschlag and Bhere, 2001 b; Gu et al., 2008; Li and Gu, 2008; Roth and Amory, 2011).

\section{Testosterrone implant}

Implant consists of pure testosterone and one time application showed efficacy comparable to weekly testosterone enanthate injection. However the disadvantage of minor surgery required for implantation under the abdominal skin is compensated by their low price (Nieschlag and Bhere, 2001 ).

\section{Transdermal testosterone}

Testosterone patches are a successful approach to the treatment of male hypogonadism, but they do not appear to be an effective method of androgen administration for male contraception, probably because the lower peak serum levels of testosterone are unable to effectively suppress gonadotropin secretion from the pituitary. In addition, skin reactions to the patch are a problem (Amory, 2008). Now a days testosterone gel are used which are acceptable to nearly all men and potently suppress spermatogenesis in combination with injectable medroxyprogesterone acetate (Page et al., 2006).

\section{Testosterone combined with gestagen}

In ordered to accelerate the onset of testosterone effectiveness and to increase azoospermia rates, combining testosterone with other gonadotropin suppressing substances was attempted. The injection need be given only every 6 weeks and no side effects were observed (Nieschlag and Bhere, 2001 ). 
Levonorgestrel

Oral administration of $0.5 \mathrm{mg}$ levonorgestrel daily in addition to weekly injection of testosterone enanthate led to faster and more effective suppression of spermatogenesis than testosterone enanthate injections alone (Nieschlag and Bhere, 2001 ${ }_{\mathrm{b}}$ ).

Testosterone combined with GnRH Agonist

Continuous administration of GnRH agonists first stimulates LH and FSH secretion, but after a certain period, blocks it by a down regulation of the GnRH receptors. The agonist naferelin were given at doses of 50-500 $\mu \mathrm{g} / \mathrm{d}$ for 10-30 weeks. Only $30 \%$ of volunteers showed decreases of sperm production under $5 \mathrm{Mio} / \mathrm{ml}$ (Nieschlag and Bhere, 2001 ${ }_{\mathrm{b}}$ ).

\section{Testosterone combined with GnRH Antagonist}

GnRH antagonists suppress LH and FSH and thus spermatogenesis from the very onset of treatment (Nieschlag and Bhere, 2001 ).

\section{Adverse effects of hormonal contraceptives}

Various studies have reported that hormonal contraceptives can causes weight gain, acne, mood change, libido changes, fatigue, aggression, disturbed sleep and reduced testicular size.

\subsection{Immuno-Contraception}

Development of a vaccine(s) established on sperm antigens signifies an encouraging methodology to contraception. The utility of a sperm antigen in immune-contraception is contingent upon its tissue specificity, involvement in fertility and on raising high antibody titer, especially locally in the genital tract, that is capable of inducing reversible infertility. Numerous sperm antigens, such as NZ-1, NZ-2, cleavage signal (CS)-1, sperm protein (SP)-10, PH-20, lactate dehydrogenase C4, fertilization antigen (FA)-1 and FA-2 have been suggested as possible candidates for the vaccine development. Sperm zona pellucida (ZP) binding is a fundamental tissue- and typically species-specific incident in the fertilization phenomenon, and the molecules participate in this location constitute the most exciting candidates for immuno-contraception. FA-1 is a sperm-specific glycoprotein having receptor activity for ZP recognition and binding. Complementary DNA encoding for FA-1 antigen has been cloned and sequenced. Active immunization of animals with recombinant FA-1 antigen causes a long-lasting reversible inhibition in fertility by raising a sperm-specific immune response. This antigen is also involved in human immuno infertility (Naz, 1999).

3.6 Surgical Methods: It includes the following methods

\section{Vasectomy}

For birth control vasectomy is designated as a permanent method. This procedure after ejaculation inhibits the release of sperm. During this procedure, the vas deferens from each testicle is cut, clamped, or otherwise sealed. This procedure checks sperm from mingling with the semen that is ejaculated from the penis. Semen without sperm is unable to fertilized egg. Sperm are continuously produced by the testis, but are reabsorbed by the body. As these tubes 
are clamped prior to the seminal vesicles and prostate therefore, has no effects on the fluid volume during ejaculation. It usually takes several months after a vasectomy for all remaining sperm to be ejaculated or reabsorbed. You must use another method of birth control until you have a semen sample tested and it shows a zero sperm count. Otherwise, you can still get your partner pregnant (Trussell, 2007; Rakhi and Sumathi, 2011).

\section{No Scalpel Vasectomy}

This is a technique that uses a small clamp with pointed ends. Instead of using a scalpel to cut the skin, the clamp is poked through the skin of the scrotum and then opened. The benefits of this procedure include less bleeding, a smaller hole in the skin, and fewer complications. No-scalpel vasectomy is as effective as traditional vasectomy (Trussell, 2007).

\section{Vasclip implant procedure}

The vas deferens is locked closed with a device called a vasclip. The vas deferens is not cut, sutured, or cauterized (sealed by burning), which possibly reduces the potential for pain and complications. Some studies show that clipping is not as effective as other methods of sealing off the vas deferens (Trussell, 2007)

\subsection{Non-Surgical, Non-Pharmaceutical Methods}

\section{Ultrasound}

In humans, monkeys, cats and dogs this was tried as a method of sterilization. Twenty male cats for ten minutes were treated once or twice with 1 watt/sq $\mathrm{cm}$ of ultrasound. Each of 24 male dogs for ten minutes received one to three treatments with $1 \mathrm{watt} / \mathrm{sq} \mathrm{cm}$. Another six dogs for 15 minutes were treated with 2 watts/sq $\mathrm{cm}$. Four Cebus apella monkeys were treated with the same dosage as that used for the cats and dogs. A dosage of $1 \mathrm{watt} / \mathrm{sq} \mathrm{cm}$ was also applied to four human patients for 10 minutes without the use of anesthetics, and no pain or side effects were noted. In all treated animals as well as in human patients the results indicate that ultrasound significantly suppresses spermatogenesis according to the dosage and frequency of treatment, without any effect on leydig cells or blood testosterone levels (Fahim et al., 1977).

\section{Conclusion}

Studies have explained various aspects (efficacy and side effects) of different male contraceptive methods. In developing countries men are not showing interest to adopt a suitable contraceptive method. Similarly in developing countries most of the male contraceptive methods are either not available or not compatible to their cultural norms. Some of the methods are irreversible or very expensive, while others have either severe side effect, non-reliable or not acceptable to their partner. Therefore in these scenarios, to control the population explosion there is an intense need to develop a suitable, feasible, safe and reliable male contraceptive method that is acceptable in all societies of the world.

\section{References}

Amory, KJ. (2008). Progress and prospects in male hormonal contraception: Current opinion in endocrinology, diabetes and obesity, 15(3), 255-260. 
Besculides, M., \& Laraque, F. (2004). Unintended pregnancy among the urban poor. Journal of Urban Health, 81, 340-348. http://dx.doi.org/10.1093/jurban/jth122

Cosentino, MJ. Pakyz, RE., \& Fried J. (1990). Pyrimethamine: an approach to the development of a male contraceptive: Proceedings of the national academy of sciences USA, 87(4), 1431-1435.

Chinoy, NJ. D'Souza, JM., \& Padman, P. (1995). Contraceptive efficacy of Carica papaya seed extract in male mice (Mus musculus). Phytotheraphy research, 9, 30-36. http://dx.doi.org/10.1002/ptr.2650090108

Cook, CE. Wani, MC. Jump, JM. Lee, Y-W. Fail, PA. Anderson, SA. Gu, Y-Q., \& Petrow, V. (1995). Structure activity studies of 2,3,4,4 $\alpha, 5,9 \beta$-hexahydroindeno[1,2-c]pyridines as antispermatogenic agents for male contraception. Journal of medicinal chemistry, 38,753-763. http://dx.doi.org/10.1021/jm00005a003

Cook, CE. Jump, JM. Zhang, P. Stephens, JR. Lee, Y-W. Fail, PA. Anderson, SA. (1997). Exceptionally potent antispermatogenic compounds from 8-halogenation of (4 $\alpha \mathrm{RS}, 5 \mathrm{SR}, 9 \beta \mathrm{RS})$-hexahydroindeno-[1,2-c] pyridines. Journal of medicinal chemistry, 40, 2111-2112. http://dx.doi.org/10.1021/jm00005a003

Christina, W., \& Ronald, SS. (2010). Hormonal Approaches to Male Contraception, Current Opinion in urology, 20(6), 520-524. http://dx.doi.org/10.1097/MOU.0b013e32833f1b4a

Chauhan, A. Agarwal, M. Kushwaha, S., \& Mutreja, A. (2007). Suppression of fertility in male albino rats following the administration of $50 \%$ ethanolic extract of Aegle marmelos. Contraception, 76, 474-481. http://dx.doi.org/10.1016/j.contraception.2007.08.002

Cheng, CY., \& Mruk, DD. (2010). New frontiers in non-hormonal male contraception. Contraception, 82(5), 476-482. http://dx.doi.org/10.1016/j.contraception.2010.03.017

Das, RP. (1980). Effects of papaya seed on the genital organs and fertility of male rats. Indian Journal of experimental biology, 18, 408-409.

Dixit, VP. Jain, P., \& Purohit, AK. (1992). Medicinal uses of neem (Azadirachta indica) in fertility regulation, diabetes and atherosclerosis. Rec Adv Med Aromatic Spice Crops, 2, 463-471.

Driak, D., \& Swandova, I. (2013). Blockade of calcium channels - a perspectiveof male contraception: Ceska Gynekol, 78(2), 216-20.

Fahim, MS. Fahim, Z. Harman, J. Thompson, I. Montie, J., \& Hall, DG. (1977). Ultrasound as a new method of male contraception: Fertility and sterility, 28(8), 823-31.

Finer, LB. Henshaw, SK. (2003). Abortion incidences and services in the United States in 2000. Perspective on sexual and reproductive health, 35, 6-15. http://dx.doi.org/10.1363/3500603

Fanuel, L. (2011). Complementary and Alternative Medicines: The Herbal Male Contraceptive. African journal of traditional, complementary and alternative medicine, 8, 5 . 


\section{Macrothink}

Journal of Biology and Life Science ISSN 2157-6076 2015, Vol. 6, No. 1

Goto, A. Yasumura, S. Yabe, J., \& Reich, MR. (2006). Addressing Japan's fertility decline: influences of unintended pregnancy on child rearing. Reproductive health Matters, 14, 191-200. http://dx.doi.org/10.1016/S0968-8080(06)27233-1

$\mathrm{Gu}$, YQ et al. (2008). Multicenter contraceptive efficacy trial of injectable testosterone undecanoate in Chinese men. Journal of clinical endocrinology and metabolism. http://dx.doi.org/10.1210/jc.2008-1846

Henshaw, SK. (1998). Unintended pregnany in the United States. Family planning Perspectives, 30, 24-29. http://dx.doi.org/10.2307/2991522

Hild, SA. Reel, JR. (2000). Age-dependent effects of CDB-4022 on testicular function and fertility in male rats. Proc 33rd Annual Meeting of the Society for the Study of Reproduction, University of Wisconsin, Madison, WI, p 337 (Abstract 588).

Hay, CJ. Brady, DM. Zitzmann, M. et al. (2005). A multicenter phase IIb study of a novel combination of intramuscular androgen (testosterone decanoate) and oral progestogen (etonogestrel) for male hormonal contraception. Journal of clinical endocrinology and Metabolism, 90, 2042-2049. http://dx.doi.org/10.2307/2991522

Hogarth, AC. Amory, KG. Griswold, M. (2011). Inhibiting Vitamin A Metabolism As An Approach To Male Contraception: Trends in endocrinology and metabolism, 22(4), 136-144. http://dx.doi.org/10.1016/j.tem.2011.01.001

Hogarth, AC. Evanoff, R., \& Griswold, DM. (2011). Suppression of Stra8 Expression in the Mouse Gonad by WIN 18,446: Biology of reproduction, 84(5), 957-965. http://dx.doi.org/10.1095/biolreprod.110.088575

IIPS \& ORG Macro. (2000). National family health survey-2: India. 1998-99. Mumbai: International Institute for Population Sciences.

Jha, KR. Jha, KP. Guha, KS. (2009). Smart RISUG: A potential new contraceptive and its magnetic field-mediated sperm interaction: International journal of nano-medicine, 4, 55-64. http://dx.doi.org/10.2147/IJN.S4818

Kasturi, M. Manivannan, B. Nazeer, AR. Shaikh, PD. Pathan, KM. (1995). Changes in epididymal structure and function of albino rat treated with Azadirachta indica leaves. Indian Journal of experimental biology, 33, 725-729.

Kenjale, R. Shah, R., \& Sathaye, S. (2008). Effects of Chlorophytum borivilianum on sexual behaviour and sperm count in male rats. Phytother Res, 22, 796-801. http://dx.doi.org/10.1002/ptr.2369

Lohiya, NK. Ravi, BG. (1992). Antifertility investigations on the crude chloroform extract of Carica papaya seeds in male albino rats. Indian journal of experimental biology, 30, 1051-1055.

Ly, LP. Liu, PY. Handelsman, DJ. (2005). Rates of suppression and recovery of human sperm output in testosterone-based hormonal contraceptive regimens. Human reproduction, 20, 
1733-1740. http://dx.doi.org/10.1093/humrep/deh834

Li, Jw. Gu, YQ. (2008). Predictors for partial suppression of spermatogenesis of hormonal male contraception. Asian journal of andrology, 10, 723-730. http://dx.doi.org/10.1111/j.1745-7262.2008.00432.x

Mavi, S. (2000). Personal communication. Harare, Zimbabwe.

Mruk, DD. Silvestrini, B., \& Cheng, Y. (2008). Anchoring Junctions As Drug Targets: Role in Contraceptive Development: Pharmacology review, 60(2), 146-180. http://dx.doi.org/10.1124/pr.107.07105

Mishra, RK. Singh, SK. (2009). Antispermatogenic and antifertility effects of fruits of Piper nigrum L. in mice. Indian journal of experimntal biology, 47(9), 706-714.

Neischlag, E., \& Bhere, HM. (2001). A text book of Andrology, $2^{\text {nd }}$ edition, springer (New York), Chapter 20, Page no. 401.

Neischlag, E. Bhere, HM. (2001) $)^{\mathrm{a}}$. A text book of Andrology, $2^{\text {nd }}$ edition, springer (New York), Chapter 20, Page no. 410.

Neischlag, E. Bhere, HM. (2001) $)^{\mathrm{b}}$. A text book of Andrology, $2^{\text {nd }}$ edition, springer (New York), Chapter 20, Page no. 411.

Page, ST. Amory, JK. Anawalt, BD. (2006). Testosterone gel combined with depomedroxyprogesterone acetate (DMPA) is an effective male hormonal contraceptive regimen but is not enhanced by the addition of the GnRH antagonist acyline. Journal of clinical endocrinology and metabolism, 91, 4374-4380. http://dx.doi.org/10.1210/jc.2006-1411

Qian, SZ. Zhong, CQ. Xu, Y. (1986). Effect of Tripterygium wilfordii on the fertility of rats. Contraception, 33, 105-110. http://dx.doi.org/10.1016/0010-7824(86)90076-4

Qian, SZ. (1987). Tripterygium wilfordii: a Chinese herb effective in male fertility regulation. Contraception, 36, 247-263.

Rakhi, J. Sumathi, M. (2011). Journal of obstetrics and gynecology of India, 61, 6.

Rao, MV. Shah, KD. Rajani, M. (1997a). Contraceptive effects of Phyllanthus amarus extract in the male mouse. Phytotheraphy research, 11, 594-596.

Rao, MV. Shah, KD. Rajani, M. (1997b). Contraceptive efficacy of Balanites roxburghii pericarp extract in male mice (Mus musculus). Phytotheraphy research, 11(11), 469-471.

Naz, RK. (1999). Vaccine for contraception targeting sperm: Immunology review, 171, 193-202. http://dx.doi.org/10.1111/j.1600-065X.1999.tb01349.x

Roth, MY. Amory, JK. (2011). Pharmacologic Development of Male Hormonal Contraceptive Agents. Clinical pharmacology and therapeutics, 89(1), 133-36. http://dx.doi.org/10.1038/clpt.2010.103

Shaikh, PD. Manivannan, B. Pathan, KM., \& Nazeer, A. (1993). Antispermatic activity of 


\section{Macrothink}

Azadirachta indica leaves in albino rats. Current science, 64, 688-689.

Sailaja, K. Hild AS, Attardi.JB (2008), Mechanism of Action of l-CDB-4022, Potential Nonhormonal Male Contraceptive, in the Seminiferous Epithelium of the Rat Testis: Endocrinology, 149(4), 1850-1860. http://dx.doi.org/10.1210/en.2007-1332

Sewani-Rusike, CR. Gundidza, M. (2011). Antifertility Effects of Oldenlandia Affinis in Male Rats-a Preliminary Study: African Journal of traditional, complementary and alternative medicine, 8, 4.

Trussell, J. (2007). Choosing a contraceptive: Efficacy, safety, and personal considerations. Contraceptive Technology: 19th ed., pp. 19-47. New York: Ardent Media.

Yu, DY. (1983). One hundred and forty-four cases of rheumatoid arthritis treated with Tripterygium wilfordii. Journal of traditional Chinese medicines, 3, 125-129.

World Health Organization (1996). Task Force on methods for the regulation of male Contraceptive efficacy of testosterone-induced azoospermia and oligozoospermia in normal men. Fertility and sterility, 65(4), 821-9.

Zheng, JR. Fang, JL. Xu, LF. (1985). Effect of total glycosides of T. wilfordii on reproductive organs of male rats. Acta Academicae Medicae Sinicae, 7, 256-259.

\section{Copyright Disclaimer}

Copyright for this article is retained by the author(s), with first publication rights granted to the journal.

This is an open-access article distributed under the terms and conditions of the Creative Commons Attribution license (http://creativecommons.org/licenses/by/3.0/). 